\title{
DEVELOPMENT OF A MULTI-OBJECTIVE PRODUCTION PLANNING MODEL FOR A SAWMILL
}

\author{
SEGUN ABIODUN ALONGE ${ }^{* 1}$, CHRISTOPHER OSITA ANYAECHE ${ }^{1}$ \\ ${ }^{1}$ Department of Industrial and Production Engineering, University of Ibadan, Ibadan, \\ Nigeria
}

\begin{abstract}
Based on the objectives set out for a Sawmill, a goal programming model was developed to simultaneously consider the production volumes goal, sales revenue goal, production cost goal, and machine utilization goal in order to develop its production plans for a horizon. The unwanted deviations from the goals served as the objective function to be optimized subject to the goals constraints, operational constraints, and non-negativity constraints. Three independent pre-emptive goal priority structures, GP1, GP2, and GP3, were considered with each prioritizing the objectives differently. The goal programming model was tested for its utility using data gathered from the mill to the three-goal priority structures. The results obtained indicated that, for GP1, the product volume goals for all products were achieved, and all but one, volume goals were achieved for both GP2 and GP3. The viability test showed that all priority structures used were profitable with GP1, GP2, and GP3 recording 1.099, 1.102, and 1.095 respectively. This indicates that the three priority structures considered are approximately profitable at the same level. The goal programming model for production planning offers the decision-maker a variety of options as to its application.
\end{abstract}

Keywords: sawmills, goal programming model, goals constraints, priority structures, production plans

\section{INTRODUCTION}

Production planning is a complex task that entails cooperation among several functional units in any manufacturing organization [1]. According to Ozdamar et al. [2], planning is the consequence of a hierarchy of decisions dealing with different issues in the manufacturing environment. In order to design an efficient production planning system, a good understanding of the environment in terms of customers, products, and manufacturing processes is a must $[3,4]$. Production planning in a product oriented organization can be used as a way of checkmating resources wastage both in the inputs and the outputs from such producing company.

This is evident in the case of wooden furniture industry in Indonesia as Susanty et al. [5] investigated production planning model in the form of circular economy to solve the problems faced by the traditional wooden furniture industry in Indonesia which include inefficient use of raw materials and production process. In similar researches [6-7], found that the circular economy has positive impact on the waste management and led to efficient production processes in the specific production industries in which it was applied.

Although production planning is common with products oriented industries but not limited in practice to only such organizations. It is a fact that production planning model has proven to be very useful in construction industries too $[8-12]$.

\footnotetext{
*Corresponding author, email: segunalonge95@yahoo.com
}

(C) 2021 Alma Mater Publishing House 
Although production planning exists in the company, it is often incorrectly structured, using a linear programming method, which is not totally effective due to the fact that the problem consists of multiple conflicting objectives [1]. A number of optimization tools exist which include; linear programming, goal programming, genetic and evolutionary algorithm, etc. that can be used to develop a production planning model in relation to the organization requirements [13-15].

This work was designed to develop a production planning system for multi-objective criteria, and applied on the production processes in sawmills. The sawmilling industries generally turn out a wide range of products (sawnwoods) produced in different cross-sectional sizes which include: 1 x $2 ; 1$ x $3 ; 1$ x $6 ; 1$ x 12 (planks); 2 x 2; 2 x 3 ; $2 \times 4 ; 2 \times 6 ; 2 \times 12$; and $3 \times 4$, with all measurements being in inches. These are largely produced based on customers' request, funding power as well as the log (round-wood) conversion (manufacturing) processes. There is therefore the need for optimizing the production process so as to meet the market demand for the products at a minimized production cost, avoiding the underutilization of the processing machines, and maximizing the sales revenue.

The conditions for production are multiple which makes the optimization problem a multi-objective one, and since it is a known fact that linear programming method cannot deal with multi-objective problems except to minimize or maximize an objective function. This gap has been bridged through the development of the Goal Programming (GP) model, which can simultaneously consider as many as possible conflicting objectives [16].

The objective of this study was to develop a goal programming (GP) production planning model for production planning in the selected sawmills and apply the model to demonstrate its utility and give recommendations.

The insight gained from this study will:

i. Guide and assist decision-makers in the sawmilling industry in achieving the industry's goals of optimum utilization of resources to the improvement of the industry's profit;

ii. Guide the sawmilling firms in production planning;

iii. Help the industry to forecast its production per period/season;

iv. Assist in Optimization/Operational Research students for further research.

\section{GOAL PROGRAMMING}

Goal programming is a deviation of linear programming that allows multiple-objectives (goals), and soft (goals) constraints, or a combination of soft and hard (non-goal) constraints that can deviate, allowing for trade-offs in achieving a satisficing somewhat than only optimal solution.

Kliestik et al [17], presented goal programming as a special approach for solving tasks of linear programming. Charnes et al. [18] first pointed out goal programming and presented it as a constrained regression idea that embodies the deviation minimizing approach inherent in goal programming. However, the term goal programming firstly appeared in 1961, in a book by Charnes and Cooper [19]. Note that it was not presented as a unique method, but as an extension to the general linear programming approach, and suggested for solving unsolvable linear programming methods.

\subsection{Application of Goal Programming (GP) Models}

For production planning in a toothpaste production factory a goal programming model was developed, Adeyeye, and Charles-Owaba [20]. Mansoureh and Hadi [21], proposed the goal programming model for aggregate production planning after comparing the result obtained from a Linear programming approach to those of the Goal Programming approach, and the latter was found better for a tile production factory. A goal programming model was developed for estimating the base potential in productivity evaluation and performance measurements in the manufacturing and service sectors by Oluleye and Raji [22]. In order to promote business successes and improve profit generation in small and medium scale enterprises Kanakana-Katumba and Makinde [23], proposed a goal programming model that could be used to optimally plan production operations in a bottled water manufacturing enterprise. Anyaeche and Mogbojuri [24] applied GP in project Portfolio selection. Other applications of GP can be seen as demonstrated by [25-29]. 


\subsection{Goal Programming Algorithms}

There are two methods used for the solution of goal programming as recorded by [30]. These are the weighted method, in which a single objective function is formed as the weighted sum of the functions representing the goals of the problem, and the pre-emptive method, that starts by prioritizing the goals in a scale of preference.

\subsubsection{The Weight Method}

In this method, relative weights are assigned to the detrimental deviations, which act as per unit penalty for not achieving a set goal. The goal programming model is converted to a linear programming model with the sole objective of minimizing the total weighted deviation from the goals. Suppose the goal programming model has $n$ number of goals $\mathrm{M}$, and the $i^{t h}$ goal is given as: minimize $M_{i}$, where $i$ is $1,2,3, \ldots n$.

The combined objectives functions used in the weights method can be defined as equation (1):

$$
\text { Minimize } Z=w_{1} M_{1}+w_{2} M_{2}+w_{3} M_{3}+\ldots \ldots .+w_{n} M_{n}
$$

The parameters $w_{i}, i=1,2,3, \ldots n$, are positive weights that reflect the preferences of the decision-makers regarding the relative importance of each goal.

\subsubsection{The Pre-Emptive Method}

In this method, the decision-maker has to rank the goals of the problem in order of importance. For an n-goals problem situation, the objectives are written as equation (2):

$$
\text { Minimize } \mathrm{M}_{1}=\mathrm{P}_{1} \text { (Highest Priority): Minimize } \mathrm{M}_{\mathrm{n}}=\mathrm{P}_{\mathrm{n}} \text { (Lowest Priority) }
$$

This implies that the decision maker wants to do the best to achieve the first priority goal $\left(\mathrm{P}_{1}\right)$, after which he then considers the second priority $\left(\mathrm{P}_{2}\right)$, and the third priority goal $\left(\mathrm{P}_{3}\right)$, and so on till the nth goal.

The variable $P_{i}$ is the component of the deviational variables $\mathrm{d}^{-}$, or $\mathrm{d}^{+}$that represents goal $\mathrm{i}$.

Note: The equality sign is appropriate because it shows that $\mathrm{M}_{1}$ represents the highest priority $\left(\mathrm{P}_{1}\right)$.

\section{DEVELOPMENT OF THE MULTI-OBJECTIVES GOALS}

\subsection{Model's Assumptions}

(i) Variety of products, differentiated by sizes, are derived from a single raw material and product's number denoted by $\mathrm{i}$ (where $\mathrm{i}$ is $1,2,3, \ldots, \mathrm{m}$ );

(ii) A material may have to go through one or more machines to become a finished product. Machine number denoted by $\mathrm{j}(\mathrm{j}$ is $1,2, \ldots \mathrm{n})$;

(iii) All parameters for the model are constant throughout the planning horizon;

(iv) No shortage of raw materials for the planning horizon;

(v) All products are of grade one.

The details of variables and the objective functions representing the performance criteria are presented as follows.

\subsection{Notation}

(a) Indices

$\mathrm{i}=$ Product type $(\mathrm{i}=1,2, \ldots, \mathrm{m})$;

$\mathrm{j}=$ Machine type $(j=1,2, \ldots, n)$.

(b) Decision parameters

$\mathrm{y}_{\mathrm{ij}}=$ Machine capacity required for the processing of product $\mathrm{i}$ from machine $\mathrm{j}$;

$\mathrm{c}_{\mathrm{i}}=$ Production cost of product I;

$\mathrm{s}_{\mathrm{i}}=$ Sales revenue realized from the product I;

$U_{j}=$ Total available machine capacity for the resources $j$.

(c) Decision variables

$\mathrm{x}_{\mathrm{i}}=$ Volume of Production (numbers of sawn-wood) of type $\mathrm{i}$ to be produced per period; 


\subsection{The Performance Criteria Used}

The performance criteria incorporated into the model include:

\subsubsection{Production Volume $(V)$}

$$
\text { Maximize } \mathrm{V}=\mathrm{x}_{\mathrm{i}}
$$

where $\mathrm{V}$ is products volume and $\mathrm{x}_{\mathrm{i}}$ is sum of product $\mathrm{i}$.

Equation (1) is the same as that of the production volume criteria used by Chowdary and Slomp [1].

The manufacturing process conditions to include the production cost, machine utilization, and sales revenue criteria are as follow.

\subsubsection{Total Production Cost (TPC)}

$$
\text { Minimize TPC }=\sum_{i}^{m} c_{i} x_{i}
$$

where, TPC is Total Production Cost, $\mathrm{c}_{\mathrm{i}} \mathrm{i}$ - production cost per unit of product $\mathrm{i}$ including quality cost, $\mathrm{x}_{\mathrm{i}}$ - same as in 3.3.1, and $\mathrm{m}$ - quantity of product types.

\subsubsection{Total Machine Utilization (U)}

$$
\text { Maximise } \mathrm{U}_{\mathrm{j}}=\sum_{i}^{m} y_{i j} x_{i}
$$

where, $\mathrm{U}_{\mathrm{j}}$ is Total machine utilization capacity; $\mathrm{y}_{\mathrm{ij}}$ - machine capacity required by machine $\mathrm{j}$ for processing a unit of product $\mathrm{i}, \mathrm{x}_{\mathrm{i}}$ - same as in 3.3.1, and $\mathrm{m}$ - same as defined in 3.3.2.

According to [13] the machine capacity utilization directly affects the speed of response to customers' demand.

\subsubsection{Total Sales Revenue (TSR)}

$$
\text { Maximize TSR }=\sum_{i}^{m} s_{i} x_{i}
$$

where, TSR is total sales revenue; $\mathrm{s}_{\mathrm{i}}$ - sales revenue per unit of product $\mathrm{i} ; \mathrm{x}_{\mathrm{i}}$ - same as in 3.3.1, and $\mathrm{m}$ - as defined in 3.3.2.

\subsection{Estimation of the Goal Programming Model's Parameters}

All model parameters are assumed to be deterministic and constant during the planning horizon. The parameters and estimation of their values are described below.

\subsubsection{Machine capacity required and available}

This is estimated based on the time needed for the processing of one unit of product $\mathrm{i}$ on machine resource $\mathrm{j}$.

\subsubsection{Production cost}

The total cost of production per product $\left(\mathrm{c}_{\mathrm{i}}\right)$ is estimated as the sum of machine costs, tool costs, transportation costs, and other costs to include the quality cost (prevention and failure costs). Only direct investment costs are included in the machine costs.

\subsubsection{Sales revenue}

This parameter, sales revenue $\left(\mathrm{s}_{\mathrm{i}}\right)$, depends on the company's sales target in the planning horizon. The marketing department is given the task of forecasting the demand which is assumed to be deterministic.

\subsection{Formulation of the GP Model}

3.5.1. Product volumes goal

The requirements with respect to the aggregate product volumes of product 1 to product 10 , which is the sum of all customer orders in the planning period, are to be met. Both the negative deviations $\left(d_{i}^{-}\right)$and the positive 
deviations $\left(d_{i}^{+}\right)$of the goal must be considered in the objective function in order to achieve the desired exact product volume. Therefore, the goal can be presented as: minimize $\left(d_{i}^{+}+d_{i}^{-}\right)$, subject to:

$$
x_{i}+d_{i}^{-}-d_{i}^{+}=\mathrm{V}_{\mathrm{i}}
$$

where, $\mathrm{i}$ is $1,2,3, \ldots, 10 ; d_{i}^{+}, d_{i}^{-}$- over and underachievement of product i volume goal respectively; $\mathrm{V}_{\mathrm{i}}$ - market goal on product 1 volume (aggregate) as per prediction (goal) up to market goal on product 10 volume (aggregate) as per prediction (goal).

The minimization of $d_{i}^{-}+d_{i}^{+}$will minimize the absolute value of $\mathrm{x}_{\mathrm{i}}-\mathrm{V}_{\mathrm{i}}$. This implies that; in order to get the $\mathrm{xs}$ that achieve the goal $x_{i}=V_{i}$ exactly, both the negative and positive deviations of the product volume need to be minimized.

\subsubsection{Sales revenue goal}

Due to past sales records, the management feels that the sales goal for the next period should be ' $R$ ' naira. And the achievement of the sales revenue goal, which will be set at $R$, is a function of the total gross margin of the products 1 to 10 respectively. The goal is presented as: minimize $\left(d_{11}^{-}\right)$, subject to:

$$
\sum_{i=1}^{10} s_{i} x_{i}+d_{11}^{-}-d_{11}^{+}=\mathrm{R}
$$

where, $d_{11}^{+}, d_{11}^{-}$are over and underachievement of sales revenue goal; $\mathrm{R}$ is sales revenue goal fixed by the management.

The over achievement of sales goals is acceptable here, and therefore positive derivation from the goal is eliminated from the objective function. The solution set will consist of all x's such that $\sum_{i=1}^{10} s_{i} x_{i} \geq \mathrm{R}$ by minimizing $d_{11}^{-}$to zero if such a solution is possible in the model. If it is not possible to minimize $d_{11}^{-}$to zero, the solution set will consist of all x's that minimize $\left(\mathrm{R}-\sum_{i=1}^{10} s_{i} x_{i}\right)$ to the extent possible.

\subsubsection{Production cost goal}

The goal of minimizing the production cost for the product volumes of products 1 to 10 can be represented as: minimize $\left(d_{12}^{+}\right)$, subject to:

$$
\sum_{i=1}^{10} c_{i} x_{i}+d_{12}^{-}-d_{12}^{+}=0
$$

where, $d_{12}^{+}, d_{12}^{-}$are over and under achievement in production cost goal.

The solution here identifies all x's which satisfy $\sum_{i=1}^{10} c_{i} x_{i} \leq 0$, provided such a solution is possible. If the model cannot minimize $\left(d_{12}^{+}\right)$to zero, the solution consists of all x's that minimize $\sum_{i=1}^{10} c_{i} x_{i}$ to the fullest possible extent.

\subsubsection{Machine capacity utilization goal}

Here there is the need for the minimization of the underutilization of machines. Therefore the negative deviation $\left(d_{13}^{-}\right)$from the goal is to be eliminated or reduced to the barest minimum from the objective function. The goal of minimizing the underutilization of the machines is presented as: minimize $\left(d_{13}^{-}\right)$, subject to:

$$
\sum_{i=1}^{10} y_{i j} x_{i}+d_{13}^{-}-d_{13}^{+}=\mathrm{U}_{\mathrm{j}}
$$

where, $y_{i j}$ is machine capacity required for the processing of product $i$ from machine $j$, and $j=1,2 ; U_{j}$ - available capacity of the machine $\mathrm{j}$ (goal); $d_{13}^{+}, d_{13}^{-}$- over time and idle capacity required for the operation of machine $\mathrm{j}$.

\subsection{The Pre-emptive Goal Programming Priority Structures}

Three independent goal priority structures were considered in order to test the pre-emptive GP model. In addition to the variables and constraints stated above the pre-emptive priority factors for the three finalized goal structures are defined as follows.

\subsubsection{Goal Priority Structure 1}

Here the product volume/market goal is given the preference over the manufacturing process cost of production goals. 
$\mathrm{P}_{1}$ (Priority 1$)=$ the highest priority, and it is assigned to the satisfaction of product demands. Both deviations (negative and positive) from the 10 product demands (i.e $d_{i}^{+}+d_{i}^{-}$) should be minimized;

$\mathrm{P}_{2}$ (Priority 2) = the second priority factor, it is assigned to the machine utilization goal. That is the minimization of the underachievement of machine utilization $\left(d_{13}^{-}\right)$;

$\mathrm{P}_{3}$ (Priority 3$)=$ Here we minimized the underachievement deviation, $d_{11}^{-}$, and the overachievement deviation, $d_{12}^{+}$, for sales revenue and production cost respectively.

The model for priority structure 1 is now formulated. The objective is the minimization of the deviations from the various goals imposed by the production planning environment.

The model can be expressed as equation (11):

$$
\begin{gathered}
\text { Minimize } \mathrm{Z}_{1}=\mathrm{P}_{1}\left(d_{1}^{+}+d_{1}^{-}+d_{2}^{+}+d_{2}^{-}+d_{3}^{+}+d_{3}^{-}+d_{4}^{+}+d_{4}^{-}+d_{5}^{+}+d_{5}^{-}+d_{6}^{+}+d_{6}^{-}+d_{7}^{+}+d_{7}^{-}+w_{8}^{+}+\right. \\
\left.d_{8}^{-}+d_{9}^{+}+d_{9}^{-}+d_{10}^{+}+d_{10}^{-}\right)+\mathrm{P}_{2}\left(d_{13}^{-}\right)+\mathrm{P}_{3}\left(d_{11}^{-}+d_{12}^{+}\right)
\end{gathered}
$$

Subject to, constraints (7) to (10) and provided that:

$$
\begin{gathered}
x_{1}, x_{2}, x_{3}, x_{4}, x_{5}, x_{6}, x_{7}, x_{8}, x_{9}, x_{10}, \geq 100, \\
d_{1}^{+}, d_{1}^{-}, d_{2}^{+}, d_{2}^{-}, d_{3}^{+}, d_{3}^{-}, d_{4}^{+}, d_{4}^{-}, d_{5}^{+}, d_{5}^{-}, d_{6}^{+}, d_{6}^{-}, d_{7}^{+}, d_{7}^{-}, d_{8}^{+}, d_{8}^{-}, d_{9}^{+}, d_{9}^{-}, d_{10}^{+}, d_{10}^{-}, d_{11}^{+}, d_{11}^{-}, d_{12}^{+}, d_{12}^{-}, d_{13}^{+}, \\
d_{13}^{-} \geq 0 .
\end{gathered}
$$

\subsubsection{Goal Priority Structure 2}

Here the machine utilization goal (First Priority $\mathrm{P}_{1}$ ) is given preference over the sales revenue and production costs goals (Second Priority $\mathrm{P}_{2}$ ) and the product volume/market demand goals (Third Priority $\mathrm{P}_{3}$ ).

Now the overall GP model for priority structure 2 is represented as equations (12):

$$
\begin{gathered}
\text { Minimize } \mathrm{Z}_{2}=\mathrm{P}_{1}\left(d_{13}^{-}\right)+\mathrm{P}_{2}\left(d_{11}^{-}+d_{12}^{+}\right)+\mathrm{P}_{3}\left(d_{1}^{+}+d_{1}^{-}+d_{2}^{+}+d_{2}^{-}+d_{3}^{+}+d_{3}^{-}+d_{4}^{+}+d_{4}^{-}+d_{5}^{+}+d_{5}^{-}+\right. \\
\left.d_{6}^{+}+d_{6}^{-}+d_{7}^{+}+d_{7}^{-}+d_{8}^{+}+d_{8}^{-}+d_{9}^{+}+d_{9}^{-}+d_{10}^{+}+d_{10}^{-}\right)
\end{gathered}
$$

Subject to; Constraints (7) to (10), and provided that:

$$
\begin{gathered}
x_{1}, x_{2}, x_{3}, x_{4}, x_{5}, x_{6}, x_{7}, x_{8}, x_{9}, x_{10}, \geq 100, \\
d_{1}^{+}, d_{1}^{-}, d_{2}^{+}, d_{2}^{-}, d_{3}^{+}, d_{3}^{-}, d_{4}^{+}, d_{4}^{-}, d_{5}^{+}, d_{5}^{-}, d_{6}^{+}, d_{6}^{-}, d_{7}^{+}, d_{7}^{-}, d_{8}^{+}, d_{8}^{-}, d_{9}^{+}, d_{9}^{-}, d_{10}^{+}, d_{10}^{-}, d_{11}^{+}, d_{11}^{-}, d_{12}^{+}, d_{12}^{-}, d_{13}^{+}, \\
d_{13}^{-} \geq 0
\end{gathered}
$$

In this model, the objective function $Z_{2}$ indicates the total of the un-attained portions of the goals of the production planning.

\subsubsection{Goal Priority Structure 3}

Here the achievement of products 1 to 5 is of utmost concern and so it is given the highest priority, then followed by the minimization of the production cost as well as achieving the market demand for product 6 to 10 (second priority) after which the sales revenue goal and machine utilization were considered (third priority).

Now the overall GP model for priority structure 2 is represented as equation (13):

$$
\begin{gathered}
\text { Minimize } \mathrm{Z}_{3}=\mathrm{P}_{1}\left(d_{1}^{+}+d_{1}^{-}+d_{2}^{+}+d_{2}^{-}+d_{3}^{+}+d_{3}^{-}+d_{4}^{+}+d_{4}^{-}+d_{5}^{+}+d_{5}^{-}\right)+\mathrm{P}_{2}\left(d_{12}^{+}+d_{6}^{+}+d_{6}^{-}+d_{7}^{+}+\right. \\
\left.\left.d_{7}^{-}+w_{8}^{+}+d_{8}^{-}+d_{9}^{+}+d_{9}^{-}+d_{10}^{+}+d_{10}^{-}\right)\right)+\mathrm{P}_{3}\left(d_{11}^{-}+d_{13}^{-}\right)
\end{gathered}
$$

Subject to; Constraints (7) to (10), and provided that:

$$
\begin{gathered}
x_{1}, x_{2}, x_{3}, x_{4}, x_{5}, x_{6}, x_{7}, x_{8}, x_{9}, x_{10}, \geq 100, \\
d_{1}^{+}, d_{1}^{-}, d_{2}^{+}, d_{2}^{-}, d_{3}^{+}, d_{3}^{-}, d_{4}^{+}, d_{4}^{-}, d_{5}^{+}, d_{5}^{-}, d_{6}^{+}, d_{6}^{-}, d_{7}^{+}, d_{7}^{-}, d_{8}^{+}, d_{8}^{-}, d_{9}^{+}, d_{9}^{-}, d_{10}^{+}, d_{10}^{-}, d_{11}^{+}, d_{11}^{-}, d_{12}^{+}, d_{12}^{-}, d_{13}^{+}, \\
d_{13}^{-} \geq 0
\end{gathered}
$$


In the above model, $Z_{3}$ in the objective function can be interpreted as the total of the un-attained portions of production planning goals.

\section{MODEL APPLICATION}

\subsection{Data Presentation}

The developed model is tested using as inputs the data gathered from the firm based on personal observations and oral interviews. Then the data for a particular month was calculated. A sample of these input data is given in Table 1 for all of the pre-emptive goal priority structures. Each priority structure was executed using LINGO software package for 2015 (LINGO.15) with $\mathrm{P}_{1}=100, \mathrm{P}_{2}=10$, and $\mathrm{P}_{3}=1$. These were assumed arbitrarily based on the company's management policies.

Table 1. Sample Input Data.

\begin{tabular}{|c|c|c|c|c|c|c|c|}
\hline \multirow[t]{2}{*}{$\mathrm{S} / \mathrm{N}$} & \multirow{2}{*}{$\begin{array}{c}\mathrm{x}_{\mathrm{i}} \text { (Inches by } \\
\text { Inches) }\end{array}$} & \multirow[t]{2}{*}{$\mathrm{V}_{\mathrm{i}}$} & \multirow[t]{2}{*}{$\mathrm{S}_{\mathrm{i}}(\mathrm{N} 1000)$} & \multirow[t]{2}{*}{$\mathrm{C}_{\mathrm{i}}(\mathrm{N} 1000)$} & \multicolumn{2}{|c|}{$\mathrm{y}_{\mathrm{ij}}$ (hours) } & \multirow{2}{*}{$\begin{array}{c}\mathrm{Y}_{\mathrm{ij}}=\left(\mathrm{y}_{\mathrm{i} 1}+\mathrm{y}_{\mathrm{i} 2}\right) \\
\text { (Hours) }\end{array}$} \\
\hline & & & & & $\mathrm{j}=1$ & $\mathrm{j}=2$ & \\
\hline 1 & 1" by 2" & 900 & 0.175 & 0.155 & 0.02 & 0.01 & 0.03 \\
\hline 2 & 1" by 3" & 600 & 0.250 & 0.235 & 0.02 & 0.01 & 0.03 \\
\hline 3 & 1" by 6" & 900 & 0.500 & 0.485 & 0.02 & 0.01 & 0.03 \\
\hline 4 & 1" by $12 "$ & 6000 & 1.150 & 1.105 & 0.02 & 0.00 & 0.02 \\
\hline 5 & 2" by 2" & 1500 & 0.275 & 0.255 & 0.02 & 0.015 & 0.035 \\
\hline 6 & 2" by 3" & 1200 & 0.425 & 0.385 & 0.02 & 0.015 & 0.035 \\
\hline 7 & 2" by 4" & 1200 & 0.550 & 0.500 & 0.02 & 0.015 & 0.035 \\
\hline 8 & 2" by 6" & 900 & 0.800 & 0.725 & 0.02 & 0.015 & 0.035 \\
\hline 9 & 2" by $12 "$ & 750 & 1.600 & 1.400 & 0.02 & 0.00 & 0.02 \\
\hline 10 & 3" by 4" & 750 & 0.800 & 0.715 & 0.025 & 0.02 & 0.045 \\
\hline
\end{tabular}

Note: All costs $c_{i} /$ sales prices $\mathrm{s}_{\mathrm{i}}$, figures are in thousand naira; Processing machines' capacities, and $\mathrm{y}_{\mathrm{ij}}$, are in hours.

\subsection{Application of the GP Model}

With all symbols and representation as defined earlier, the goal programming is presented and applied. Therefore using the data so presented in Table 1 the GP model is set up as follows in accordance with the priorities earlier defined.

\subsubsection{Goal Priority Structure 1}

The multi-objective function is equation (14):

$$
\begin{array}{r}
\operatorname{Min} \mathrm{Z}_{1}=100\left(d_{1}^{+}+d_{1}^{-}+d_{2}^{+}+d_{2}^{-}+d_{3}^{+}+d_{3}^{-}+d_{4}^{+}+d_{4}^{-}+d_{5}^{+}+d_{5}^{-}+d_{6}^{+}+d_{6}^{-}+d_{7}^{+}+d_{7}^{-}+d_{8}^{+}+d_{8}^{-}+\right. \\
\left.d_{9}^{+}+d_{9}^{-}+d_{10}^{+}+d_{10}^{-}\right)+10\left(d_{13}^{-}\right)+1\left(d_{11}^{-}+d_{12}^{+}\right)
\end{array}
$$

Subject to:

$$
\begin{aligned}
& \mathrm{x}_{1}+d_{1}^{-}-d_{1}^{+}=900 ; \\
& \mathrm{x}_{2}+d_{2}^{-}-d_{2}^{+}=600 ; \\
& \mathrm{x}_{3}+d_{3}^{-}-d_{3}^{+}=900 ; \\
& \mathrm{x}_{4}+d_{4}^{-}-d_{4}^{+}=6000 ; \\
& \mathrm{x}_{5}+d_{5}^{-}-d_{5}^{+}=1500 ; \\
& \mathrm{x}_{6}+d_{6}^{-}-d_{6}^{+}=1200 ; \\
& \mathrm{x}_{7}+d_{7}^{-}-d_{7}^{+}=1200 ;
\end{aligned}
$$




$$
\begin{gathered}
\mathrm{x}_{8}+d_{8}^{-}-d_{8}^{+}=900 ; \\
\mathrm{x}_{9}+d_{9}^{-}-d_{9}^{+}=750 ; \\
\mathrm{x}_{10}+d_{10}^{-}-d_{10}^{+}=750 ; \\
0.175 \mathrm{x}_{1}+0.25 \mathrm{x}_{2}+0.5 \mathrm{x}_{3}+1.15 \mathrm{x}_{4}+0.275 \mathrm{x}_{5}+0.425 \mathrm{x}_{6}+0.55 \mathrm{x}_{7}+0.8 \mathrm{x}_{8}+1.6 \mathrm{x}_{9}+0.8 \mathrm{x}_{10}+d_{11}^{-}-d_{11}^{+}=13000 ; \\
0.155 \mathrm{x}_{1}+0.235 \mathrm{x}_{2}+0.485 \mathrm{x}_{3}+1.05 \mathrm{x}_{4}+0.255 \mathrm{x}_{5}+0.385 \mathrm{x}_{6}+0.5 \mathrm{x}_{7}+0.725 \mathrm{x}_{8}+1.4 \mathrm{x}_{9}+0.715 \mathrm{x}_{10}+d_{12}^{-}-d_{12}^{+}=0 ; \\
(26) \\
0.03 \mathrm{x}_{1}+0.03 \mathrm{x}_{2}+0.03 \mathrm{x}_{3}+0.02 \mathrm{x}_{4}+0.035 \mathrm{x}_{5}+0.035 \mathrm{x}_{6}+0.035 \mathrm{x}_{7}+0.035 \mathrm{x}_{8}+0.02 \mathrm{x}_{9}+0.045 \mathrm{x}_{10}+d_{13}^{-}-d_{13}^{+}= \\
400 ; \\
\mathrm{x}_{1} \geq 100 ; \mathrm{x}_{2} \geq 100 ; \mathrm{x}_{3} \geq 100 ; \mathrm{x}_{4} \geq 100 ; \mathrm{x}_{5} \geq 100 ; \mathrm{x}_{6} \geq 100 ; \mathrm{x}_{7} \geq 100 ; \mathrm{x}_{8} \geq 100 ; \mathrm{x}_{9} \geq 100 ; \mathrm{x}_{10} \geq 100 ;(26) \\
d_{1}^{+}, d_{1}^{-}, d_{2}^{+}, d_{2}^{-}, d_{3}^{+}, d_{3}^{-}, d_{4}^{+}, d_{4}^{-}, d_{5}^{+}, d_{5}^{-}, d_{6}^{+}, d_{6}^{-}, d_{7}^{+}, d_{7}^{-}, d_{8}^{+}, d_{8}^{-}, d_{9}^{+}, d_{9}^{-}, d_{10}^{+}, d_{10}^{-}, d_{11}^{+}, d_{11}^{-}, d_{12}^{+}, d_{12}^{-}, d_{13}^{+}, \\
(28)
\end{gathered}
$$

\subsubsection{Goal Priority Structure 2}

The multi-objective function is equation (30):

$$
\begin{gathered}
\operatorname{Min} \mathrm{Z}_{2}=1\left(d_{1}^{+}+d_{1}^{-}+d_{2}^{+}+d_{2}^{-}+d_{3}^{+}+d_{3}^{-}+d_{4}^{+}+d_{4}^{-}+d_{5}^{+}+d_{5}^{-}+d_{6}^{+}+d_{6}^{-}+d_{7}^{+}+d_{7}^{-}+d_{8}^{+}+d_{8}^{-}+\right. \\
\left.d_{9}^{+}+d_{9}^{-}+d_{10}^{+}+d_{10}^{-}\right)+100\left(d_{13}^{-}\right)+10\left(d_{11}^{-}+d_{12}^{+}\right)
\end{gathered}
$$

Subject to; constraints; (15) to (29).

\subsubsection{Goal Priority Structure 3}

The multi-objective function is equation (31):

$$
\begin{array}{r}
\operatorname{Min} \mathrm{Z}_{3}=100\left(d_{1}^{+}+d_{1}^{-}+d_{2}^{+}+d_{2}^{-}+d_{3}^{+}+d_{3}^{-}+d_{4}^{+}+d_{4}^{-}+d_{5}^{+}+d_{5}^{-}\right)+10\left(d_{6}^{+}+d_{6}^{-}+d_{7}^{+}+d_{7}^{-}+d_{8}^{+}+\right. \\
\left.d_{8}^{-}+d_{9}^{+}+d_{9}^{-}+d_{10}^{+}+d_{10}^{-}+d_{12}^{+}\right)+1\left(d_{11}^{-}+d_{13}^{-}\right)
\end{array}
$$

Subject to; Constraints; (15) to (29).

\section{MODEL RESULTS AND DISCUSSION}

\subsection{Results}

The results as presented by the software LINGO.15 showed the optimal output volume of variables, the slacks and surpluses as well as the objective functions $Z_{1}, Z_{2}$, and $Z_{3}$ values.

The objective values $11911.75,118521.5$, and 108962.5 for GP1, GP2, and GP3 respectively, represent the values of unattained portions of the production planning goals.

The high values of $Z_{2}$ and $Z_{3}$ are due to the fact that there are portions of the high priorities $\left(\mathrm{P}_{1}\right.$ and $\left.\mathrm{P}_{2}\right)$ that were not fully minimized in the objective functions.

Tables 2, 3, 4 and 5 respectively present a summary of the results for the three priority structures.

Table 2. Summary of the GP Model Output for P1.

\begin{tabular}{|c|c|c|c|c|c|}
\hline \multirow{2}{*}{$\begin{array}{c}\text { Performance } \\
\text { criteria }\end{array}$} & $\begin{array}{c}\text { Market demand } \\
\left(\mathrm{V}_{\mathrm{i}}\right)\end{array}$ & $\begin{array}{c}\text { Optimum } \\
\text { production } \\
\text { volume }\left(\mathrm{x}_{\mathrm{i}}\right)\end{array}$ & \multicolumn{2}{|c|}{ Deviation variables } & \multirow{2}{*}{ Remarks } \\
\cline { 4 - 6 } $\begin{array}{c}\text { Products } \\
\text { Output }\end{array}$ & $\mathrm{V}_{1}=900$ & $\mathrm{x}_{1}=900$ & 0.00 & $d_{i}^{+}$ & \\
\cline { 2 - 5 } & $\mathrm{V}_{2}=600$ & $\mathrm{x}_{2}=600$ & 0.00 & 0.00 & Achieved \\
\hline
\end{tabular}




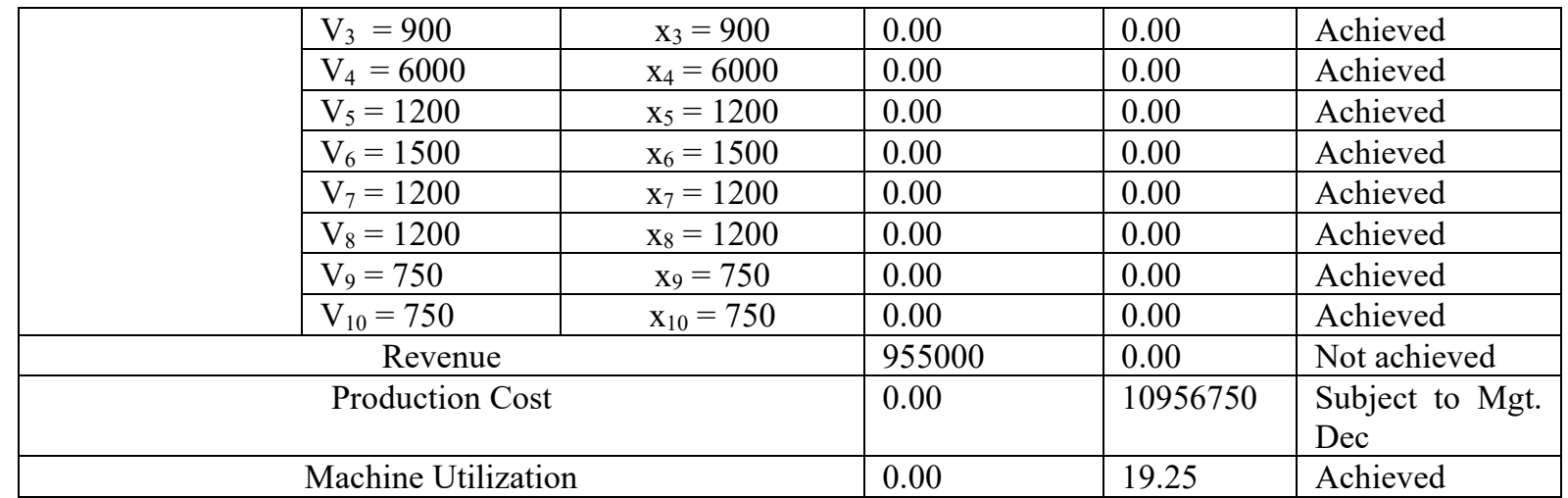

Note: All cost and sales revenue are in naira, over/underutilization of processing machine is in hours.

Table 3. Summary of the GP model output for P2.

\begin{tabular}{|c|c|c|c|c|c|}
\hline \multirow{2}{*}{$\begin{array}{l}\text { Performance } \\
\text { criteria }\end{array}$} & \multirow{2}{*}{$\begin{array}{l}\text { Market demand } \\
\qquad\left(\mathrm{V}_{\mathrm{i}}\right)\end{array}$} & \multirow{2}{*}{$\begin{array}{l}\text { Optimum } \\
\text { production volume } \\
\left(\mathrm{x}_{\mathrm{i}}\right)\end{array}$} & \multicolumn{2}{|c|}{ Deviation variables } & \multirow[t]{2}{*}{ Remarks } \\
\hline & & & $d_{i}^{-}$ & $d_{i}^{+}$ & \\
\hline \multirow[t]{10}{*}{ Output } & $\mathrm{V}_{1}=900$ & $\mathrm{x}_{1}=900$ & 0.00 & 0.00 & Achieved \\
\hline & $V_{2}=600$ & $x_{2}=600$ & 0.00 & 0.00 & Achieved \\
\hline & $\mathrm{V}_{3}=900$ & $\mathrm{x}_{3}=900$ & 0.00 & 0.00 & Achieved \\
\hline & $\mathrm{V}_{4}=6000$ & $\mathrm{x}_{4}=6000$ & 0.00 & 0.00 & Achieved \\
\hline & $\mathrm{V}_{5}=1200$ & $\mathrm{x}_{5}=1200$ & 0.00 & 0.00 & Achieved \\
\hline & $\mathrm{V}_{6}=1500$ & $\mathrm{x}_{6}=1500$ & 0.00 & 0.00 & Achieved \\
\hline & $\mathrm{V}_{7}=1200$ & $\mathrm{x}_{7}=1200$ & 0.00 & 0.00 & Achieved \\
\hline & $\mathrm{V}_{8}=1200$ & $x_{8}=1200$ & 0.00 & 0.00 & Achieved \\
\hline & $V_{9}=750$ & $\mathrm{X}_{9}=1346$ & 0.00 & 596 & Not achieved \\
\hline & $\mathrm{V}_{10}=750$ & $\mathrm{x}_{10}=750$ & 0.00 & 0.00 & Achieved \\
\hline \multicolumn{3}{|l|}{ Sales Revenue } & 1400 & 0.00 & Not achieved \\
\hline \multicolumn{3}{|c|}{ Production Cost } & 0.00 & 11791150 & $\begin{array}{l}\text { Subject to Mgt. } \\
\text { Dec }\end{array}$ \\
\hline \multicolumn{3}{|c|}{ Machine Utilization } & 0.00 & 31.17 & Achieved \\
\hline
\end{tabular}

Note: All cost and sales revenue are in naira, over/underutilization of processing machine is in hours.

Table 4. Summary of the GP Model Output for P3.

\begin{tabular}{|c|c|c|c|c|c|}
\hline \multirow{2}{*}{$\begin{array}{l}\text { Performance } \\
\text { criteria }\end{array}$} & \multirow{2}{*}{$\begin{array}{l}\text { Market demand } \\
\qquad\left(\mathrm{V}_{\mathrm{i}}\right)\end{array}$} & \multirow{2}{*}{$\begin{array}{c}\text { Optimum } \\
\text { production } \\
\text { volume }\left(\mathrm{x}_{\mathrm{i}}\right)\end{array}$} & \multicolumn{2}{|c|}{ Deviation variables } & \multirow[t]{2}{*}{ Remarks } \\
\hline & & & $d_{i}^{-}$ & $d_{i}^{+}$ & \\
\hline \multirow[t]{10}{*}{ Output } & $\mathrm{V}_{1}=900$ & $\mathrm{x}_{1}=900$ & 0.00 & 0.00 & Achieved \\
\hline & $\mathrm{V}_{2}=600$ & $x_{2}=600$ & 0.00 & 0.00 & Achieved \\
\hline & $\mathrm{V}_{3}=900$ & $\mathrm{x}_{3}=900$ & 0.00 & 0.00 & Achieved \\
\hline & $\mathrm{V}_{4}=6000$ & $\mathrm{x}_{4}=6000$ & 0.00 & 0.00 & Achieved \\
\hline & $\mathrm{V}_{5}=1200$ & $\mathrm{X}_{5}=1200$ & 0.00 & 0.00 & Achieved \\
\hline & $\mathrm{V}_{6}=1500$ & $\mathrm{x}_{6}=1500$ & 0.00 & 0.00 & Achieved \\
\hline & $\mathrm{V}_{7}=1200$ & $\mathrm{x}_{7}=1200$ & 0.00 & 0.00 & Achieved \\
\hline & $\mathrm{V}_{8}=1200$ & $\mathrm{X}_{8}=1200$ & 0.00 & 0.00 & Achieved \\
\hline & $\mathrm{V}_{9}=750$ & $\mathrm{x}_{9}=100$ & 650 & 0.00 & Not achieved \\
\hline & $\mathrm{V}_{10}=750$ & $\mathrm{x}_{10}=750$ & 0.00 & 0.00 & Achieved \\
\hline \multicolumn{3}{|c|}{ Sales Revenue } & 1995000 & 0.00 & Not achieved \\
\hline \multicolumn{3}{|c|}{ Production Cost } & 0.00 & 10046750 & $\begin{array}{l}\text { Subject to Mgt. } \\
\text { Decision }\end{array}$ \\
\hline \multicolumn{3}{|c|}{ Machine Utilization } & 0.00 & 6.25 & Achieved \\
\hline
\end{tabular}

Note: All cost and sales revenue are in naira, over/underutilization of processing machine is in hours. 
Table 5. A Test of viability of the three goal priority structure results.

\begin{tabular}{|l|l|l|l|l|l|l|}
\hline $\begin{array}{c}\text { Goal priority } \\
\text { structures }\end{array}$ & $\begin{array}{c}\text { Total } \\
\text { optimum } \\
\text { products } \\
\text { volume }\end{array}$ & $\begin{array}{c}\text { Minimized } \\
\text { production } \\
\text { cost (C) } \\
\text { (Naira) }\end{array}$ & $\begin{array}{c}\text { Total sales } \\
\text { Revenue } \\
\text { achievable } \\
\text { (R) (Naira) }\end{array}$ & $\begin{array}{c}\text { Machines usage } \\
\text { (Hours) }\end{array}$ & $\begin{array}{c}\text { Viability } \\
\text { test }\left(\frac{R}{C}\right)\end{array}$ & Remarks \\
\hline GP1 & 15000 & 10956750 & 12045000 & 19.25 (overtime) & 1.099 & Profitable \\
\hline GP2 & 15596 & 11791150 & 12998600 & 31.17 (overtime) & 1.102 & Profitable \\
\hline GP3 & 14350 & 10046750 & 11005000 & 6.25 (overtime) & 1.095 & Profitable \\
\hline
\end{tabular}

\subsection{Discussion of the Results}

The variability of the GP model is evident in its use in the three priority structures (GP1, GP2, and GP3). For the four objectives of product volume (market demand), production cost, sales revenue, and machine utilization analysed, a comparison of the result obtained in each of the structures is done and left for the decision-makers to make their decision.

GP1 achieved the market demand objectives by minimizing all deviations to the minimum possible with a total production cost of N10,956,750.00, with sales revenue of N12,045,000.00. Which is N955,000.00 less than the $\mathrm{N} 13,000,000.00$ set as the sales revenue target. The 400 hours available for machine utilization is not enough to achieve the market demand. As a result, there is a need for overtime usage of a period of 19.25 hours.

On the other hand, the GP2 priority structure has an over-achievement of 596 of a particular product thereby having 596 pieces of product 9 more than the market demand. This implies that GP2 was not able to minimize all product volume deviations to the minimum possible. A minimum production cost of $\mathrm{N} 11,791,150.00$ is required. If the company is able to sell the excess produced, the sales revenue would be N12,998,600.00, N1,400 less than the $\mathrm{N} 13,000,000.00$ target. This priority requires an overtime period of 31.17 hours, 11.92 hours more than that of GP1 which explains the higher production cost.

GP3 had an underachievement of 650 pieces of product 9 off its market demand. Like GP2, GP3 was not also able to minimize all deviations from the product volume. The minimum production cost given by the LINGO.15 software is N10,046,750.00. The achievable revenue from sales is N11,005000.00, this amount is N1,995,000.00 adrift of the N13,000,000.00 set target. GP3 has the lowest period of overtime of 6.25 hours, this explains why it has the lowest production cost compared to GP1 and GP2.

Generally, from the results of the MOGP model, it can be seen that the model performs well in communicating the trade-offs among the various performance measures to various functional levels of the organization such as marketing, sales, finance, and operations. These cost figures are useful for these departments for routine planning and scheduling. There are some instances when the product demand goals would have crossed the targets, resulting in higher costs. But these instances are found to be rare, and at the most maybe seen once in three occasions of product scenarios. However, the over-achievements are not as serious as in any way, the information can be used as a basis to arrive at an appropriate production plan.

From Table 6, it can be deduced that GP2 gives the best combination of objectives (best prioritization of objectives). But this is left for the decision-makers to play with according to objectives they are dealing with and make their choices from the available results to them.

Table 6. An Evaluation of the Model Results of the Competing Goal Priorities.

\begin{tabular}{|l|l|l|l|l|}
\hline S/N & Goal priority & Cost $(\mathrm{C})$ & Revenue $(\mathrm{R})$ & \multicolumn{1}{c|}{ Comparison of goal priorities } \\
\hline 1 & GP3 & 10046750 & 11005000 & $\frac{R_{1}-R_{3}}{C_{1}-C_{3}}=\frac{12045-11005}{10956.75-10046.75}=\frac{1040}{910}=1.14$ \\
\hline 2 & GP1 & 10956750 & 12045000 & 1.14 \\
\hline 3 & GP1 & 10956750 & 12045000 & $\frac{R_{2}-R_{1}}{C_{2}-C_{1}}=\frac{12998.6-12045}{11791.15-10956.75}=\frac{953.6}{834.4}=1.14$ \\
\hline 4 & GP2 & 11791150 & 12998600 & \\
\hline
\end{tabular}

\section{SUMMARY AND CONCLUSION}

The applications of goal programming models to real-life production problems have been on the increase in the past several years as a powerful decision-making tool for problems that involve multiple and conflicting objectives. 
Modern production systems could be complex due to the fact that there is increased uncertainty in customer demands, competitive markets, and rapid technological developments.

In this work, a multi-objective goal programming (MOGP) model was developed for production planning in sawmills. The usefulness of the model so developed was demonstrated using a set of data obtained from one of the local sawmills considered. The problem was solved by adopting the optimization software, LINGO 15.0, and the solution presented as obtained.

The results of the MOGP model as obtained from the LINGO 15.0 optimization software solution are of significance to the production manager in decision making for short-run production planning and scheduling of processing machines. The results can also be useful to other functional areas such as marketing and finance departments for routine planning.

These results are expected to guide the production manager to estimate the effects of product mix changes on the load conditions of the processing machines. In this way, the MOGP output may act as a link between the industry's broad strategies and tactical plans that enable it to achieve its goals. However, the costs of achieving goals at the expense of others must be considered by the three bodies; customers, manufacturers, and competitors, and must reach acceptable equilibrium in the accomplishment of their various goals.

Having completed the development of a multi-objective goal programming model for production planning and its utility demonstrated, the following conclusions are drawn:

i. Selected sawmills have been investigated for the wood conversion processes, machines used, and the output from the sawmills;

ii. A goal programming model that can be used for production planning in sawmills was developed;

iii. The goal programming model utility was demonstrated through a set of data obtained from an operating local sawmill. The model also offers decision-makers flexibility, since the conflicting objectives could be prioritized and considered simultaneously.

\section{REFERENCES}

[1] Chowdary, B., Slomp, J., Production planning under dynamic products environment; A multi-objective Goal Programming Approach, Research Report 02A12, University of Groningen, Research Institute, SOM (Systems Organisations and Management), 2002.

[2] Ozdamar, L., Bozyel, M.A., Birbil, S.I., A hierarchical decision support system for production planning (with case study), European Journal of Operation Research, vol. 104, 1998, p. 403-422.

[3] Tabucanon, R., Majumder, S., Production planning in a ship repairing company in Bangladesh, Bangkok, Asian Institute of Technology, 1989, p. 47-61.

[4] Olhager, J., Wikner, J., Production planning and control tools, Production Planning and Control, vol. 11, no. 3, 2000, p. 210-222.

[5] Susanty, A., Tjahjono, B., Sulistyani, R.E., An investigation into circular economy practices in the traditional wooden furniture industry, Production Planning and Control, 2020, p.1-13.

[6] Bocken, N.M., De Pauw, I., Bakker, C., Van der Grinten, B., Product design and business model strategies for a circular economy, Journal of Industrial and Production Engineering, vol. 33, no. 5, 2016, p. 308-320.

[7] Botezat, E., Dodescu, A., Vaduva, S., Fotea, S., An exploration of circular economy practices and performance among Romanian Producers. Sustainability, vol. 10, no. 9, 2018.

[8] Dave, B., Hamalainen, J.P., Kemmer, S., Koskela, L., Koskenvesa, A., Suggestions to Improve Lean Consstruction Planning, Paper presented at Proceedings 23rd Annual conference for the international group for lean construction, Perth, Australia, 2015, p. 193-202.

[9] Briskorn, D., Dienstknecht, M., Survey of quantitative methods in construction, Computers and Operation Research, vol. 92, 2018, p. 194-207.

[10] Dallasega, P., Rauch, E., Frosolini, M., A lean approach for real-time planning and monitoring in engineerto-order construction project, Building, vol. 8, no. 3, 2018.

[11] Dallasega, P., Revolti, A., Follini, C., Schimanski, C.P., Matt, D.T., BIM-based construction progress measurement of non-repetitive HVAC installation works, Paper presented at Proceedings 27th Annual conference of the international group for lean construction (IGLC), Dublin, Ireland, 2019, p. 819-830. 
[12] Dallasega, P., Marengo, E., Revolti, A., Strengths and shortcomings of methodologies for production planning and control of construction projects: a systematic literature review and future perspectives, Production planning and control, 2020, p. 1-27.

[13] Slack, N., Chambers, S., Harland, C., Harrison, A., Johnston, R., Operation management, London, Pitman Publishing, 2000.

[14] Hillier, F., Lieberman, G., Introduction to operations research seventh edition, in: McGraw Hill, New York, vol. 7, 2001, p. 331-340.

[15] Taha, H., Operation research, an introduction, seventh edition, In: Delhi, India: Prentice Hill, 2003, p. 347360.

[16] Orumie, U. C., Ebong, D., A glorious literature on linear goal programming algorithms, American journal of operations Research, vol. 4, 2014, p. 59-71.

[17] Kliestik, T., Application of multi criteria goal programming approach for management of the company, Applied mathematics sciences, vol. 9, no 115, 2015, p. 5715-5727.

[18] Charnes, A., Cooper, W. W., Ferguson, R. O., Optimal estimation of executive compensation by linear programming, Management science, vol. 1, 1955, p. 138-151.

[19] Charnes, A., Cooper, W., Management models and industrial application of linear programming, Wiley, New York, 1961.

[20] Adeyeye, A. D., Charles-Owaba, O., Goal programming model for production planning in a toothpaste factory, South African Journal of industrial engineering, vol. 19, no. 2, 2008, p. 197-209.

[21] Mansoureh F.R., Hadi, S., Proposing an aggregate production planning model by goal programming approach, a case study. Journal of data envelopment analysis and decision science, 2014, p. 1-13.

[22] Oluleye, A.E., Raji I.O., The development of a goal programming based productivity evaluation model, African journal of science and technology (AJST) science and engineering series, vol. 13, no. 2, 2016, p. 8-20.

[23] Kanakana-Katumba, G.M., Makinde O.A., A goal programming model for production planning in a small and medium bottled water manufacturing enterprise, Proceeding of the international conference on industrial engineering and operation management, Pretoria, South Africa, 2018, p. 1077-1084.

[24] Anyaeche, C.O., Mogbojuri, A., Goal programming model for project portfolio in selected zone in Nigeria, with worked examples (second edition) Ibadan: Bright Publishing, 2018.

[25] Romero, C., Rehman, T., Multi-criteria analysis for agricultural decisions. development in agricultural economics (second edition), Elsevier science publishers B.V., 2003.

[26] Nabendu, S., Manish, N., Goal programming, its application in management sectors; Special attention into plantation management: a review. International journal of scientific and research publications, 2(9), 2012, p. 1-6.

[27] Ekezie, D. D., Onuoha, D., Goal programming: an application to budgetary allocation of an institution of higher learning, Research journal in engineering and applied sciences, vol. 2, no. 2, 2013, p. 95-105.

[28] Wiwik, A., Retno, A. V., Raras, T., Juwita, P., Production planning optimization using goal programming method in Habibah Busana, Journal of advanced management science, vol. 3, no. 4, 2014, p. 270-275.

[29] Ajayi-Daniels, E.E., Resource optimization in a fashion firm: a goal programming approach, International Journal of management and fuzzy systems, vol. 5, no. 1, 2019, p. 14-20.

[30] Ezra, P.N., Oladugba, A.V., Ohanuba, F.O., Opara, P.N., Goal optimization of a pastry company, American journal of operation research, vol. 10, no. 1, 2020, p. 17-21. 